\title{
Re-entrainment of food intake of mature and old rats to the light-dark cycle
}

\author{
L. F. JAKUBCZAK \\ Gerontological Psychology Research Laboratory, Veterans Administration Hospital \\ St. Louis, Missouri 63125
}

\begin{abstract}
Are there age-related decrements in the re-entrainment of food intake of rats following an inversion of the light-dark cycle? An experiment using 17 male rats was carried out according to an 2 by 2 by 7 design, with repeated measures on the last two factors, representing age of rat (220 and 785 days), time of day $(0600-1800 \mathrm{~h}$ vs. $1800-0600 \mathrm{~h})$, and daysets $(0-6)$. The primary dependent variable was grams of food eaten during each 12 -h period. The results indicate that prior to the light reversal the older rats ate more during the light phase of the light-dark cycle than the younger rats, but did not differ from them during the dark phase; and that the older rats entrained their food intake at a slower absolute rate than the younger rats, but at an equal relative rate. These results suggest that senescent rats are as adaptable to changes in their environment as mature rats.
\end{abstract}

Many animal behaviors and physiological functions such as activity, eating, and sleeping are subject to rhythmic variations synchronous with the natural variation of night and day (Zucker, 1971). The existence of these internal biological clocks has been established in laboratory studies using $12 \mathrm{~h}$ periods of light and dark. These clocks are usually entrained to changes in the external environment such as light and temperature but they are not imposed on the animal by the environment and are endogenous (Aschoff, 1965; Zucker, 1971).

Eating by rats is entrained to the light-dark (L-D) cycle of illumination (Rusak \& Zucker, 1975) and occurs mainly in the dark. Information concerning the nature of the entrainment can be obtained by studying re-entrainment of eating following a complete inversion of the L-D cycle (Zucker, 1971). With an abrupt inversion of the L-D cycle, eating rhythms shift gradually rather than suddenly. Such a delay is indicative of a mechanism which acts to maintain the 24-h periodicity despite changes in environmental factors to which the rhythm is synchronized (Zucker, 1971).

In general, as organisms become older they seem to become less flexible in their responses to changes in the environment (Botwinick, 1973). While old rats (22-27 months) were somewhat poorer than younger rats (3-4 and 8-12 months) in their acquisition of a position discrimination, they were at the greatest disadvantage in acquiring the position reversal, i.e.,

This research was supported by 821 funds of the U.S. Veterans Administration (Medical Research Information System Number 0150). The treatment of animals was in accordance with the American Association for Accreditation of Laboratory Animal Care Guide for the Care and Use of Laboratory Animals. Thanks to Vern McIntosh for assistance in the collection of data, to Harold Mack for assistance in the analysis of the data which was performed on the University of Missouri Computer Network, and to Robert Goldstein for his helpful critique of the manuscript. they were inferior in learning to switch directions (Botwinick, Brinley, \& Robbin, 1962).

If older organisms are less flexible in their responses to environmental changes, then re-entrainment of eating following a complete inversion of the L-D cycle should be less rapid among older than younger rats. The results of the experiment should provide information on the capacity of the older rat to reverse a life-long entrainment of food intake (FI) to the L-D cycle.

\section{METHOD}

An experiment was carried out according to a 2 by 2 by 7 design, with repeated measures on the last two variables (Case 1, Winer, 1971), representing age of rat (220 and 785 days at start of light reversal), time of day $(0600-1800 \mathrm{~h}$ vs. $1800-0600 \mathrm{~h})$, and daysets $(0-6)$. The primary dependent variable was grams of food eaten during each 12-h period.

The subjects were 18 male $\mathrm{ACI} / \mathrm{Mai}$ rats (Microbiological Associates, Walkersville, Maryland), half in each age group. However, one old rat died before the completion of the experiment. The younger rats weighed $255.2 \mathrm{~g}(\mathrm{SD}=13.3)$, while the older rats weighed $289.9 \mathrm{~g}(\mathrm{SD}=24.3)$.

Approximately 2 months prior to the first day of light reversal, the rats were randomly assigned to rows of individual $18 \times 25 \times 18 \mathrm{~cm}$ suspended cages (V2177A, Aloe, St. Louis, Missouri), six cages per row. Within each row of cages, the two age groups were placed in alternate cages. The rats were then given powdered Purina Lab Chow (Ralston Purina Company, St. Louis, Missouri) in spill-resistant foodcups with the screen in place (LC 306A, Wahmann, Baltimore, Maryland). Food and water were available ad lib. The cages were located in a lightproof laboratory, where the temperature and humidity were regulated at $25^{\circ} \mathrm{C}$ and $50 \% \mathrm{RH}$, respectively. Fluorescent lighting was turned on automatically between 0600 and $1800 \mathrm{~h}$. When the lights were on, the intensity of light at the inside front of the cages varied between 1 and 7 footcandles, while at the back of the cages the intensity was less than 1 footcandle.

During the dark phase of the lighting cycle, a 25-W red lightbulb (General Electric) was kept on continuously, providing illumination by which to read the scales during weighing of the cups and to perform necessary maintenance 


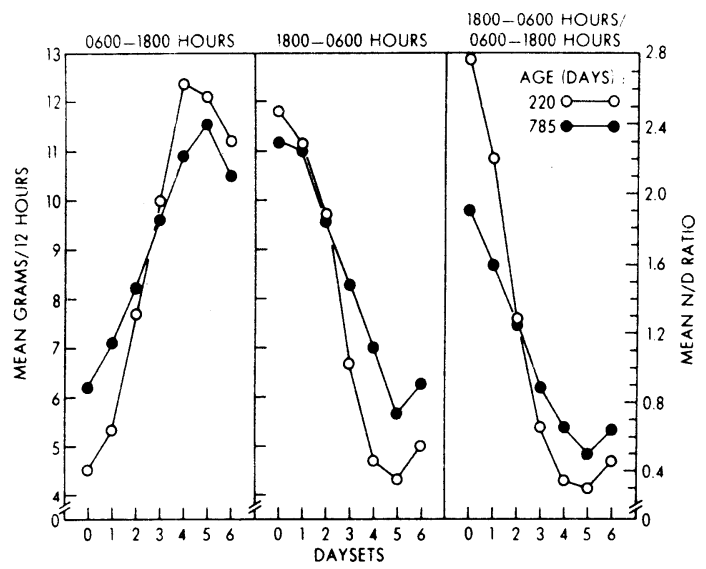

Figure 1. Grams FI and the N/D ratio as a function of age, time of day, and dayset following inversion of the light-darkness cycle.

functions. A masking noise was turned on 10 days prior to the light reversal and was on continuously throughout the reversal period in order to mask variations in noises in other parts of the building. The masking noise was produced by a noise generator (Model 901B, Grason-Stadler, West Concord, Massachusetts), using a three-way diffaxial loudspeaker (Model 312, University Sound, Oklahoma City, Oklahoma). At the rack of cages, the sound intensity was $80-82 \mathrm{~dB}$ (relative to SPL $=.0002$ microbar). Food intake was measured to the nearest $.1 \mathrm{~g}$ by weighing the foodcups twice daily at 0600 and $1800 \mathrm{~h}$, beginning 10 days before the light reversal and continuing throughout the experiment. On the appropriate day and time $(1800 \mathrm{~h})$, the light cycle was reversed (inverted $180 \mathrm{deg}$ ) so that light was on between 1800 and $0600 \mathrm{~h}$ and off between 0600 and $1800 \mathrm{~h}$. This schedule of lighting was continued until the end of this experiment 17 days later.

The appropriate 12 -h food intakes of each rat were averaged within daysets of 3 successive days. Daysets 2 and 6 , however, were based on averages of 2 days because of technical errors. The data were analyzed by means of a nonorthogonal analysis of variance (Case 1, Winer, 1971), using a general multiple regression procedure (Method 1, Overall, Spiegel, \& Cohen, 1975; Statistical Analysis System 200, Barr \& Goodnight, 1971). Unconfounded contrasts between pair of means were made by applying the multiple-range tests of Tukey to the interaction tables as recommended by Cicchetti (1972) using $\alpha=.05$.

In order to measure the relative rather than absolute rates of change of the food intakes over days, the shape function method (Anderson, 1963) was also used to analyze the data. This method corrects for differences in initial level of the dependent variable. For each rat that day was identified on which FI during a particular lighting phase or the N/D ratio (grams eaten 1800-0600 h/grams eaten 0600-1800 h) changed by one-half of the total change over the 17 days. This value constituted the dependent variable for the supplementary analyses by means of a Mann-Whitney U-test (Siegel, 1956).

\section{RESULTS}

The effects of light reversal on $\mathrm{FI} / 12 \mathrm{~h}$ depended on both age and daysets, $F(6,90)=5.83, p<.001$. After the light reversal, the food intake during the new dark phase (0600-1800 h) increased with increasing daysets (Figure 1). However, the absolute rate of increase was significantly greater among the younger rats than among the older rats, $F(6,90)=4.42, p<.001$. Furthermore, while the younger rats ate significantly less during the 0600-1800 period than the older rats prior to the light reversal, there were no age differences in FI during the last daysets. Reciprocally, the food intake during the new light phase (1800-0600 h) decreased with increasing daysets, with the rate of decrease being significantly greater among the younger rats than among the older rats, $F(6,90)=3.90, p<.01$. While there were no age differences in FI during the $1800-0600$ period prior to light reversal, the older rats tended to eat more than the younger rats during the last daysets.

These age differences in differential rates of change during the two time periods were reflected in the age differences in the rate of decrease in the N/D ratio, $F(6,90)=9.29, p<.001$ (Figure 1). The younger rats decreased their ratios at a significantly greater rate than the older rats. By the last daysets, there were no age differences with respect to this measure.

The analysis of the data by means of the shape function method failed to show significant age differences in relative rate of change of $\mathrm{FI} / 12 \mathrm{~h}$ during either the $0600-1800$ or the $1800-0600 \mathrm{~h}$ phase, or in the relative rate of change of the N/D ratio (Table 1 ), i.e., there were no age differences in the number of days necessary for the food intakes to change $50 \%$ of their total change over 17 days.

\section{DISCUSSION}

The results indicate that prior to the light reversal the older rats ate significantly more than the younger rats during the light phase of the L-D cycle, but did not differ from them during the dark phase. These results are consistent with those of Nisbett, Braver, Jusela, and Kezur (1975), who found that 10.5 -month-old male and female Wistar rats ate a significantly greater percentage of daily food intake during the light phase of the L-D cycle than did 2.5-month-old Wistar rats. The results of the present experiment confirm those of Nisbett et al (1975) and extend them to another strain, and to a greater age range. The present results, together with those of Nisbett et al (1975), are consistent with Kennedy's (1950) hypothesis that the ventromedial hypothalamus (VMH) deteriorates with age. VMH lesions result in disruption of the normal day-night differential in FI (LeMagnen, Devos, Guadilliere, Louis-Sylvestre, \& Tallon, 1973). Instead of eating primarily during the dark hours, the lesioned rat consumes $40 \%$ or more during the light hours. However, the observed age decrement in day-night differential in FI may be due in part to age decrements in sensitivity to light. Such age decrements in sensitivity to light are well established in humans (Weiss, 1959). A lowered

Table 1

Days on Which Food Intakes Were Midway Between Their Initial and Final Values

\begin{tabular}{lllll}
\hline & $\begin{array}{c}220 \\
\text { Days Old } \\
\mathrm{N}=9\end{array}$ & \multicolumn{2}{c}{$\begin{array}{c}785 \\
\text { Days Old } \\
\mathrm{N}=8\end{array}$} \\
\hline Time of Day & & & & \\
$0600-1800 \mathrm{~h}$ & 2.8 & $(.4)^{*}$ & 2.4 & $(1.1)$ \\
$1800-0600 \mathrm{~h}$ & 3.0 & $(.0)$ & 3.6 & $(.8)$ \\
N/D Ratio** & 2.4 & $(.5)$ & 2.4 & $(.9)$ \\
\hline
\end{tabular}

*Number in parentheses is standard deviation.

**Grams eaten 1800-0600 h/grams eaten 0600-1800 h. 
sensitivity to light would make the L-D differential in intensity less discriminable for the older rats, thus suppressing their FI during the light to a lesser degree than in younger rats. Diurnal cycles in young rats are influenced by intensity of light (Rusak \& Zucker, 1975). Further research is necessary to determine the mechanisms involved in these age decrements.

The results further indicate that the capacity to re-entrain FI to the reversal of light is intact over a large span of the life of the rat, and are not consistent with the hypothesis that older rats are less flexible in their responses to environmental changes. Although the older rats manifested a slower absolute rate of entrainment than the younger rats, this was due to the smaller absolute change that was required to reverse the FI pattern. Since the day-night differential in FI was less in the older than the younger rats, a smaller change was required over the 17 days. Thus, relative to the magnitude of the change required for the reversal of the FI pattern, the older rats changed their FI pattern as rapidly as the younger rats. These results are inconsistent with those of Botwinick et al (1962), wherein old rats learned a positive reversal less rapidly than younger rats. However, when Botwinick et al (1962) controlled for age differences in learning of the original task, they found no age differences in the task reversal. This suggested to them that the relative inflexibility of the old rats in the position reversal was due to an age decrement in learning capacity rather than flexibility. Be that as it may, the results of the present experiment suggest that senescent rats are as adaptable to changes in their environment as mature rats.

\section{REFERENCES}

ANDERSON, N. H. Comparison of different populations: Resistance to extinction and transfer. Psychological Review', 1963, 70. 162-179.

Aschoff, J. Circadian rhythms in man. Science, 1965, 148, $1427-1432$.
BARr, A. J., \& Goodnight, J. H. Statistical analysis system. Raleigh. N.C: North Carolina State University Press, 1971. Botwinic K, J. Aging and behavior. New York: Springer, 1973. Botwinick, J.. BRINLEY, J. F., \& Robbins, J. S. Learning a position discrimination and position reversals by SpragueDawley rats of different ages. Journal of Gerontology, 1962, 17. 315-319.

Cicchetti. D. V. Extension of multiple-range tests to interaction tables in analysis of variance: A rapid approximate solution. Psychological Bulletin, 1972, 77, 405-408.

KENNEDY, G. C. The hypothalamic control of food intake in rats. Proceedings of the Royal Society of London, 1950, 137. $535-549$

LeMagnen, J., Devos, M., Gaudilliere, J., Louis-Sylvestre, J., \& TAllon, S. Role of a lipostatic mechanism in regulation by feeding of energy balance in rats. Journal of Comparative and Physiological Psychology, 1973, 84, 1-23.

Nisbett, R. E., Braver, A., Juseal, G., \& Kezur, D. Age and sex differences in behaviors mediated by the ventromedial hypothalamus. Journal of Comparative and Physiological Psychology. 1975, 88, 735-746.

Overal.., J. E., Spiegel, K., \& Cohen, J. Equivalence of orthogonal and nonorthogonal analysis of variance. Psychologicul Bulletin, 1975, 82, 182-186.

RuzAK, B.. \& ZUCKER, I. Biological rhythms and animal behavior. Annual Review of Psychology, 1975, 26, 137-172.

SIEGEL, S. S. Nonparametric statistics. New York: McGrawHill, 1956.

Weiss. A. D. Sensory functions. In J. E. Birren (Ed.), Handbook of aging and the individual. Chicago: University of Chicago Press. 1959.

WINER, B. J. Statistical principles in experimental design (2nd ed). New York: McGraw-Hill, 1971.

ZUCKER, I. Light-dark rhythms in rat eating and drinking behavior. Physiology and Behavior, 1971, 6, 115-126.

(Received for publication August 4, 1975.) 